\title{
Multidrug resistant bacterial isolates causing nosocomial urinary tract infection in a tertiary care hospital, Nepal
}

MK Sah

\section{From 3rd International Conference on Prevention and Infection Control (ICPIC 2015)}

Geneva, Switzerland. 16-19 June 2015

\section{Introduction}

Nosocomial infection is becoming a leading problem in medical practitioners now-a-days placing an extra burden on individual patients worldwide. Nosocomial urinary tract infection caused by multidrug resistant (MDR) pathogens is a major threat of the patients in developing country which are increasing numbers in Nepal.

\section{Objectives}

The aim of this study was to determine the etiology of nosocomial urinary tract infection caused by multidrug resistant bacterial pathogens.

\section{Methods}

A total of one hundred twenty two bacterial strains isolated from the patients diagnosed of nosocomial urinary tract infection were studied during 2011-2012 at Tribhuvan University Teaching Hospital (TUTH). Antibiotic sensitivity test was determined by modified Kirby Bauer Disc Diffusion method as described by Clinical and Laboratory Standards Institute (CLSI). Data were analysed by using SPSS version 17.0 software.

\section{Results}

Nosocomial urinary tract infection was caused by Escherichia coli 51(41.8\%) was found to be more predominant which was followed by Acinetobacter calcoaceticus baumannii (Acb) complex 19(15.6\%), Klebsiella pneumoniae 11(9\%) Enterococcus spp. 18(14.8\%) and Staphylococcus aureus 11(9\%). Of the total isolates, $74.6 \%$ was MDR which is much higher in Klebsiella

Department of Clinical Microbiology, Kathmandu University, Kantipur Dental College Teaching Hospital \& Research Center, Basundhara, Kathmandu, Nepal, Kathmandu, Nepal 